\title{
Growth and development indices of Aberdeen- Angus bulls originating from sires of different body types
}

\author{
Mukhamed Shakhmurzov ${ }^{1}$, Anatoly Shevkhuzhev ${ }^{2}$, Vladimir Pogodaev, ${ }^{2}$, Vladimir \\ Gukezhev $^{3}$, and Vitaly Vorokov ${ }^{4}$ \\ ${ }^{1}$ Kabardino-Balkarian State Agricultural University named after V.M. Kokov, Lenin Avenue, 1V, \\ 360030 Nalchik, Russia \\ ${ }^{2}$ Federal State Budgetary Scientific Institution North Caucasian Federal Scientific Agrarian Center, \\ Nikonova str., 49, 546241 Mikhailovsk, Russia \\ ${ }^{3}$ Institute of agriculture KBNTs RAN, Kirov str., 224, 360024 Nalchik, Russia \\ ${ }^{4}$ Federal State Budgetary Educational Institution of Higher Education "Kuban State Agricultural \\ University named after I.T. T. Trubilin", Kalinina str., 13, 350044 Krasnodar, Russia
}

\begin{abstract}
The purpose of this work was to establish the characteristics of growth, exterior, payment for feed by gain in live weight among young Aberdeen-Angus breed, originating from bulls of different body types. Hammer LLC of Karachay-Cherkessia conducted the experiment: from the offspring of 4 large bulls and 3 small bulls of the Aberdeen-Angus breed, 14 bulls were selected in each group. The investigation results on the intensive rearing of different young stock from weaning to 18 months of age showed that large-type bulls were superior to small-type bulls in terms of growth rate and better payment for feed by gain in live weight. At the age of 18 months, bulls from large-type parents reached a weight of 442 $\mathrm{kg}$, and from small ones $-413 \mathrm{~kg}$. These differences are statistically significant $(\mathrm{P}>0.99)$ for the period from weaning to one and a half years old bulls, originating from bulls of a large type spent $8.1 \mathrm{EFU}$ per $1 \mathrm{~kg}$ of gain, and bulls originating from bulls of a small type - 8.4 EFU.
\end{abstract}

\section{Introduction}

Beef cattle breeding is the most promising and economically efficient in districts where there are large areas of natural forage lands, which include the Karachay-Cherkessia Republic $[1,2]$. Here you can keep large herds of beef cows and raise calves with full milk feeding up to 7-8 months of age, which, in combination with intensive fattening and postweaning of young stock, makes it possible to organize beef production with minimal labour costs and expenses [3-5].

In this regard, in beef cattle breeding there is a tendency towards a transition from the extreme compact (solid) type with a short and square body on low legs to a type that is larger in live weight and well-defined meat forms [6-8].

\footnotetext{
*Corresponding author: pogodaev 1954@mail.ru
} 
The Aberdeen-Angus breed, widespread in Russia, including in Karachay-Cherkessia, belongs to one of the world's best meat breeds [9-11]. However, in the last two decades, this breed has also developed towards the formation of a relatively small, but very early maturing type [12-14]. This raises the requirement of establishing the most desirable and promising type, improving the breeding methods and the methods for growing breeding young stock.

The purpose of this work was to establish the peculiarities of growth, exterior, payment for feed by gain in live weight among young Aberdeen-Angus breed, originating from stud bulls of different body types.

\section{Materials and Methods}

Hammer LLC of Karachay-Cherkessia conducted the experiment: from the offspring of 4 large bulls and 3 small bulls of the Aberdeen-Angus breed, 14 bulls were selected in each group.

The characteristics of bull parents in terms of live weight and the nature of body type are shown in Table 1.

The fathers of the first group bulls had a higher level of live weight compared to the fathers of the second group bulls (by $80 \mathrm{~kg}$ ) and differed from them in high-leggedness, less broad body and massiveness. The mothers of the first group bulls also had a higher live weight (by $49 \mathrm{~kg}$ ) in comparison with the mothers of the second group bulls, the body type differences were insignificant.

Immediately after weaning, they were placed on control rearing. The average age of the first group bulls at weaning was 8 months 22 days, and the second group bulls -8 months 20 days.

Selection according to the principle of analogs in experimental groups was based on live weight, age, health status and origin.

The first group consisted of bulls descended from stud bulls of large tall type, the second group consisted of bulls descended from stud bulls of the small compact type.

The conditions of bull feeding and keeping in experimental groups were the same and corresponded to the farm rearing system.

During the experiment, according to the methodology, the following investigations were carried out: to inspect the growth and development of the experimental animals, they were weighed monthly, when setting up for the experiment at the age of 12, 15 and 18 months, and their main body measurements were taken.

In order to identify a more complete picture of the growth tension degree for experimental animals, the relative growth rate was calculated according to the formula:

$$
\kappa=\frac{W t-W 0 * 100}{W t+W 0: 2},
$$

where $\mathrm{K}$ is the relative increase in live weight (increase in percentage over a certain period of time); Wt is the weight of animals at the end of the reference period; Wo is the weight of the animal at the beginning of the reference period.

In order to investigate the degree of payment for feed by the experimental animals, a constant accounting of consumed feed was made by weighing feed on two adjacent days with the subsequent removal of residues;

After weaning, the experimental animals were housed in the barnyard. From December to March, the animals of the experimental groups were tethered at night, the rest of the time they were kept outdoors in the bases separately in groups. Feeding during this period was 
carried out three times a day. The animals received silage and concentrates indoors, hay in troughs outside.

Beginning from April until the end of the experiment, the animals were kept with no strings in the bases and only in bad weather they were housing indoors for the night. The animals were fed from troughs located in the bases 3 times a day.

The diet of the experimental animals included: alfalfa hay; corn silage, crushed barley, compound feed and sunflower meal. The corn silage and hay were of average quality.

The needs of animals for mineral feed were met both by the ration feed and by the additional supply of salt licks and chalk.

On a ration consisting of the above feed, the animals were kept until the end of June. At the end of June, last year's hay was replaced by a new crop of alfalfa hay, as well as a small amount of green wheat and Sudanese grass.

From August 18 to the end of the experiment, the experimental animals received chopped corn.

The feeding level was designed to obtain an average daily gain of $650-750 \mathrm{~g}$ in the period from 8 to 12 months and 750-850 g from 12 to 18 months of age. The protein nutritional value of the rations during the entire rearing of the animals was quite satisfactory. The content of phosphorus and especially calcium in the ration feed corresponded to the feeding norms of the young stock.

\section{Results of the study}

The weight growth of animals is one of the main indices in the inspection of meat productivity. Thanks to its accounting, it is possible, even during the life of the animal, to fairly accurately judge the amount of meat products that can be obtained from it, the development of the whole body, its requirements for nutrients, the cost of feed per unit of gain obtained.

In our experiment, the animals were weighed in the morning before feeding.

The change in the weight growth of bulls from weaning to 18 months return on average for the groups is shown in Table 1.

Table 1. The live weight dynamics of experimental animals.

\begin{tabular}{|c|c|c|c|c|c|c|}
\hline $\begin{array}{c}\text { Age, } \\
\text { months }\end{array}$ & Group & $\mathrm{n}$ & $\mathrm{M} \pm \mathrm{m}$ & $\mathrm{G}$ & $\mathrm{Cv}$ & $\mathrm{t}_{\mathrm{d}}$ \\
\hline 8 & 1 & 14 & $203 \pm 4.8$ & 17.55 & 8.6 & 2.50 \\
\hline \multirow{2}{*}{12} & 1 & 14 & $284 \pm 5.2$ & 19.08 & 6.7 & \multirow{2}{*}{1.34} \\
& 2 & 14 & $275 \pm 3,9$ & 14.14 & 5.1 & \\
\hline \multirow{2}{*}{15} & 1 & 14 & $358 \pm 7.9$ & 28.57 & 7.9 & \multirow{2}{*}{1.32} \\
& 2 & 14 & $345 \pm 5,9$ & 21.26 & 6.2 & \\
\hline \multirow{2}{*}{18} & 1 & 14 & $442 \pm 7.4$ & 26.7 & 6.0 & \multirow{2}{*}{3.26} \\
& 2 & 14 & $413 \pm 5,0$ & 18.14 & 4.4 & \\
\hline
\end{tabular}

Biometric treatment of the live weight of the experimental bulls showed that at the age of 8,12 and 15 months, the difference between the groups was insignificant. At the end of the experiment, at the age of 18 months, the bulls of the first group exceeded in live weight the bulls of the second group somewhat less than at weaning (at 18 months by 7.0 and at 8 months by $10.3 \%$ ), however, due to a decrease in the variability of the live weight of animals within the groups, the differences between them become statistically significant ( $\mathrm{P}$ $>0.99$ ). 
The data given for changes in the amount of daily average increases (table 2) of the live weight of experimental bulls indicate that during sucking period the bulls of the first group gave higher increases than bulls of the second group.

Table 2. Change in average daily gains of experimental bulls by growth periods.

\begin{tabular}{|c|c|c|c|c|c|}
\hline \multirow{2}{*}{ Group } & \multicolumn{5}{|c|}{ Age periods, months } \\
\cline { 2 - 6 } & $0-8$ & $8-12$ & $12-15$ & $15-18$ & $0-18$ \\
\hline 1 & 754 & 675 & 822 & 933 & 770 \\
\hline 2 & 675 & 758 & 777 & 755 & 717 \\
\hline
\end{tabular}

The reason for this is the better milk yield of mothers (larger ones in the first group), because the conditions of feeding and keeping cows with suckling calves were approximately the same, the heritability of live weight at this age was rather low $(\mathrm{h}=0.28$ $0.30)$.

After weaning and up to 12 months of age, the first group bulls grew slightly worse and demonstrated average daily gains $11 \%$ lower than the second group bulls. During this period, the difference in average body weight between groups decreased from $10.3 \%$ at weaning to $3.3 \%$ at 12 months of age.

Starting from the age of 13 months, the second group bulls grew somewhat more slowly than the first group bulls, which until the end of the experiment had higher average daily gains. Over the entire experimental period, the first group bulls demonstrated average daily gains by $4.4 \%$ higher than the second group bulls and at the end of the experiment had a large live weight of $29 \mathrm{~kg}$, or $7.0 \%$.

Calculation of the relative growth rate once again confirms that up to 12 months of age the bulls of the second group had a higher growth energy compared to the bulls of the first group.

Starting from 13 months old, they lag behind in growth energy from the bulls of the first group. Both in the first and in the second group, the energy of growth decreases with a return, but in the second group this decrease occurs more sharply than in the first one (by $13.2 \%$ in group 1 and by $21.8 \%$ in group 2 ).

Feed payment is determined by the amount of nutrients expended per unit of gain. Throughout the experiment, the consumption of feed per one head, both in the first and in the second group, was practically the same. Therefore, the consumption of feed by animals in the experimental groups changed over the growing periods, corresponding to the changes in the average daily gains (Table 3 ).

In the period from 8 to 12 months of age, the bulls of the second group gave higher average daily gains and spent $6.6 \%$ less feed units on it than the bulls of the first group. Subsequently, a decrease in the average daily gain of bulls in the second group led to an increase in feed consumption by $1 \mathrm{~kg}$ of gain in comparison with the first group.

The difference in the consumption of feed per $1 \mathrm{~kg}$ of gain, both on average for the entire time of the experiment, and for individual periods, was small and amounted to $6-8 \%$. The level of digestible protein consumption by groups almost completely corresponded to the consumption of feed units.

Table 3. Feed costs per $1 \mathrm{~kg}$ of live weight gain by experimental animals according to rearing periods.

\begin{tabular}{|c|c|c|c|c|c|c|}
\hline \multirow{2}{*}{$\begin{array}{c}\text { Period } \\
\text { (month.) }\end{array}$} & \multicolumn{5}{|c|}{ Spent per 1 kg of gain } \\
\cline { 2 - 7 } & $\begin{array}{c}\text { Energetic } \\
\text { feed unit }\end{array}$ & $\begin{array}{c}\text { \% to 2nd } \\
\text { gr. }\end{array}$ & Protein, g & $\begin{array}{c}\text { \% to 2nd } \\
\text { gr. }\end{array}$ & $\begin{array}{c}\text { Energetic } \\
\text { feed unit }\end{array}$ & Protein, g \\
\hline $0-8$ & 6.0 & 93.7 & 1038 & 93.3 & 6.4 & 1113 \\
\hline $8-12$ & 9.6 & 106.6 & 1013 & 107.0 & 9.0 & 950 \\
\hline
\end{tabular}




\begin{tabular}{|c|c|c|c|c|c|c|}
\hline $12-18$ & 7.3 & 91.2 & 740 & 90.2 & 8.0 & 820 \\
\hline $8-18$ & 8.1 & 96.6 & 830 & 95.8 & 8.4 & 867 \\
\hline $0-18$ & 7.1 & 94.6 & 930 & 94.7 & 7.5 & 982 \\
\hline
\end{tabular}

The differences in the efficiency of feed use, obtained in our experience, are very insignificant and statistically uncertain.

The second index of animal growth is linear growth. Its accounting through the systematic taking of linear measurements is additional evidence of the general level of the animal development.

The main purpose of introducing measurements of animals and assessing their exterior by measurements was to make it more accurate and get rid of subjectivity, which is possible with eye assessment.

In our experiment, in order to investigate the features of linear growth and differences in the body type of bulls of compared groups, 11 basic measurements were taken (Fig. 1, 2, 3, 4).

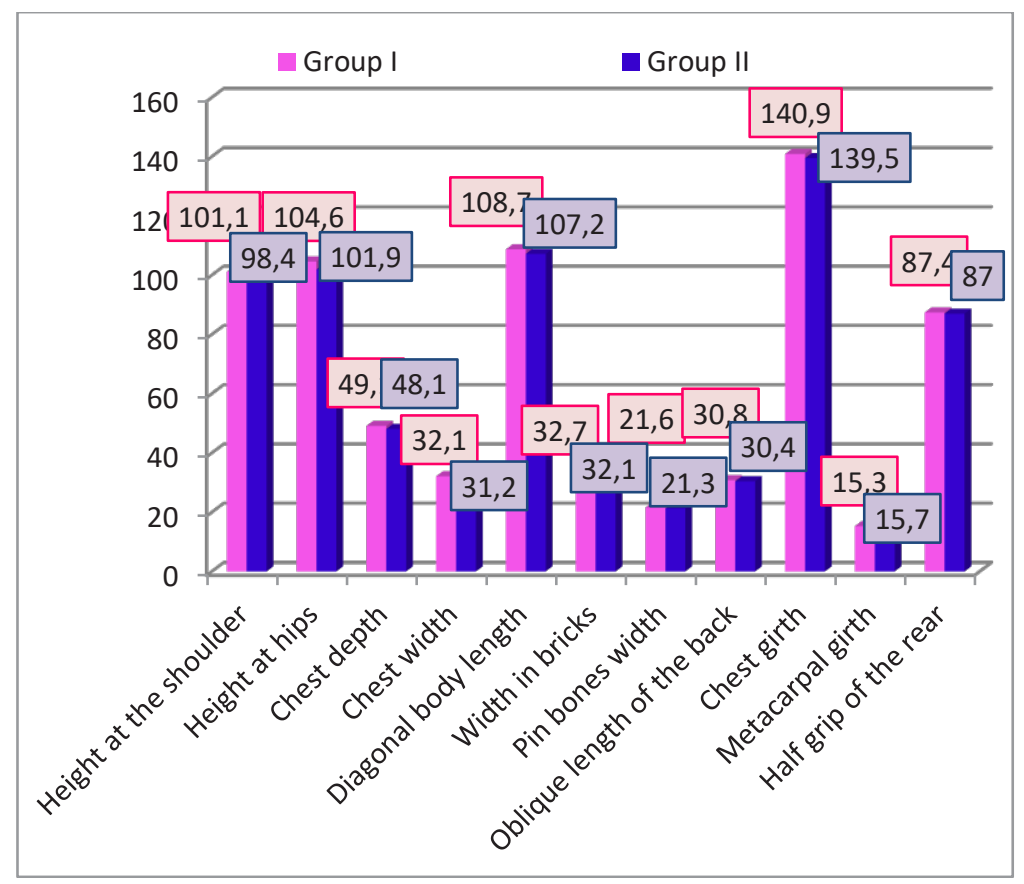

Fig. 1. Measurements of bulls body points at the age of 8 months $(\mathrm{n}=14), \mathrm{cm}$. 


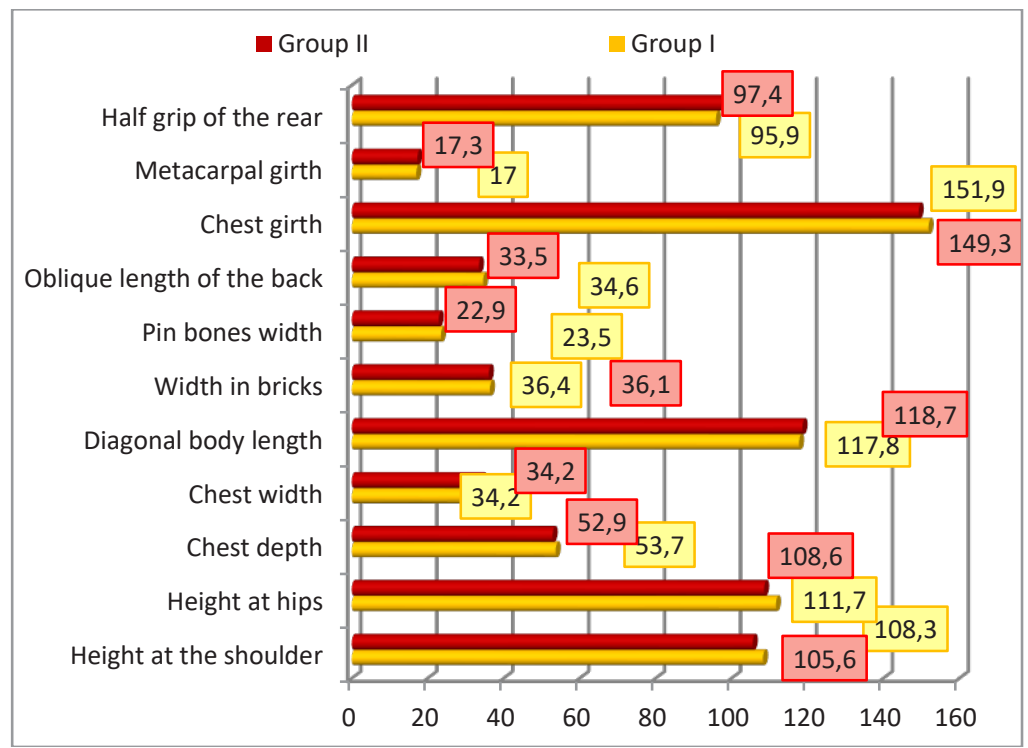

Fig. 2. Measurements of bulls body points at the age of 12 months ( $\mathrm{n}=14), \mathrm{cm}$.

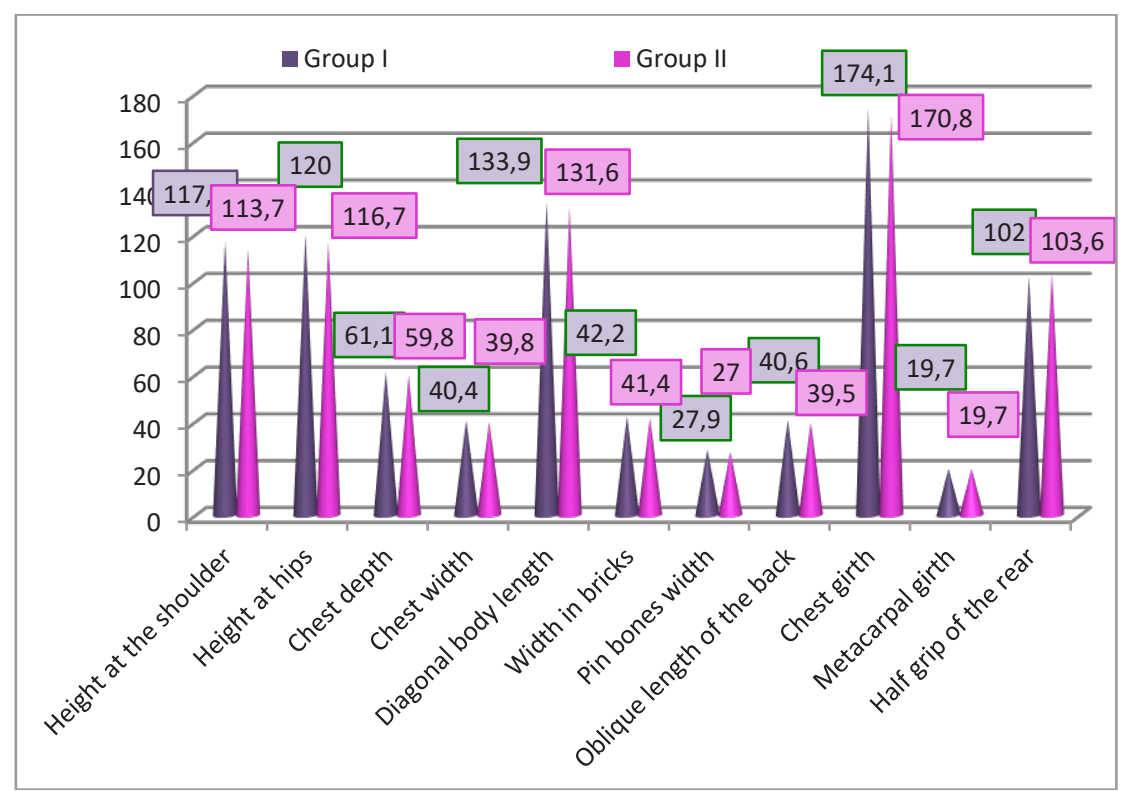

Fig. 3. Measurements of bulls body points at the age of 18 months $(\mathrm{n}=14), \mathrm{cm}$.

It was established that the animals of the first group, as larger, exceeded the animals of the second group on all measures (except semi-capture of the back) and, in particular, on such measures as height at the withers and sacrum, the depth of the chest, the oblique length of the back and the width in the pin bones. And these differences took place in all age periods. The external profile 3 shows that with age the differences in measurements changed differently. Differences in width measurements in the pin bones and oblique length of the back, slightly smaller in the depth and girth of the chest and least of all in height at the withers and sacrums, have increased the most.

The difference in the size of the chest width measurements decreased from 8 to 18 months of age. The first group bulls, who were eight months old and cede, were equal to 
the bulls of the second group in the metacarpal girth at 18 months. The double-capture pro sulfur rate, almost identical at 8 months of age, at the age of 18 months was higher for the second group.

At the end of the experiment, the most typical bulls of the first group looked relatively higher-legged and narrow-bodied.

The age changes obtained in our experience indicate that the animals of the first and second groups gave the smallest increase in height at the withers and in height at the sacrum. Measurements such as chest width, maclock width, width in the pin bones and oblique length of the back gave the greatest increase.

Age changes for animals of the first and second groups were similar. Insignificant differences were only for changing the measurements of the width in the pin bones, the oblique length of the back and the metacarpal girth. The size of these measurements, during the investigation period, increased slightly faster for bulls of the first group than the second one.

Currently, in the practice of zootechnical investigations a large number of indices is used, characterizing the body type of the animal. In our work, we used such indices which are able to most clearly show the differences in the body type nature of large tall and small compact animals. Indices of wideness, massiveness, blockiness, long-leggedness and stretch meet the task most of all.

Body indices show that the bulls of the first group in all age periods were more highlegged than the bulls of the second group, which were relatively more wide-bodied and low-legged (Figure 4, 5, 6)

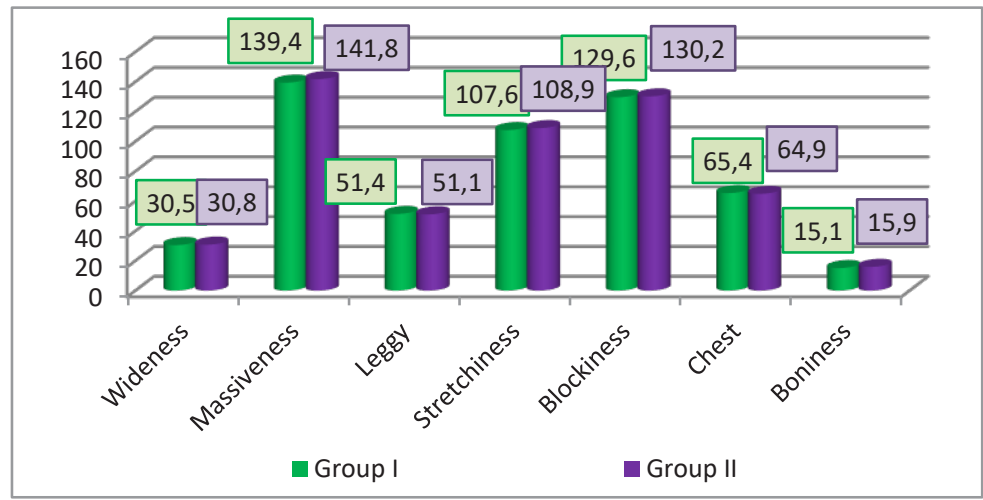

Fig. 4. Body indices of experimental bulls at 8 months, \%.

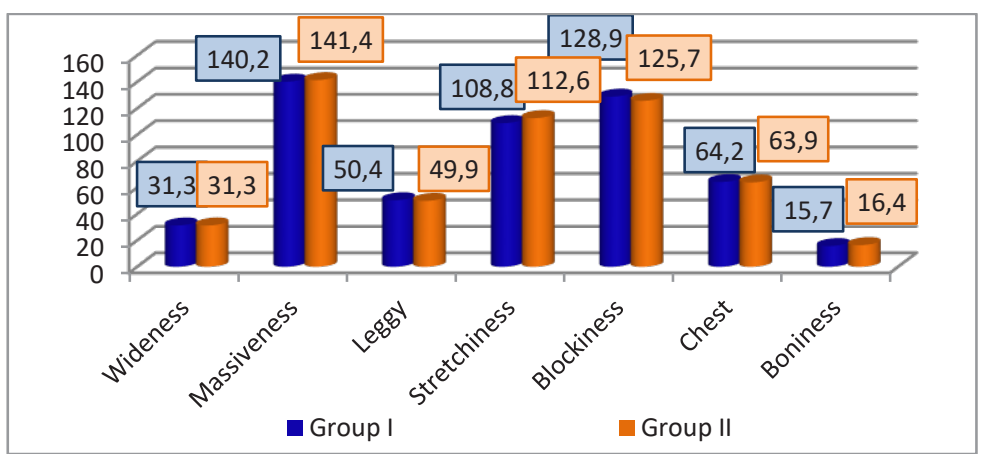

Fig. 5. Body indices of experimental bulls at 12 months, $\%$. 


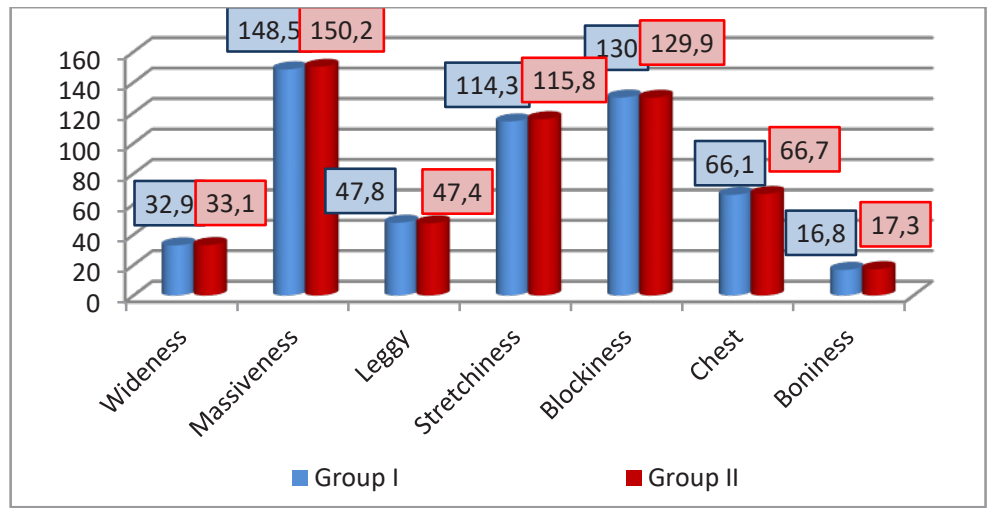

Fig. 6. Body indices of experimental bulls at 18 months, $\%$.

The bone index of the bulls of the second group was higher, because they had a shorter but relatively wider index. We see a similar picture for stud bulls. Bulls of the small compact type have the bone index $2.8 \%$ higher than bulls of the large tall type.

With age, the long-legged index decreased (by 7\%), while wideness, massiveness and stretch indices increased (by $7.9 \% ; 6.5 \% ; 6.2 \%$ for the first group and $7.5 \% ; 7.2 \% ; 6.3 \%$; for the second group). The bone index (11.3\% for the first group and $8.8 \%$ for the second group) increased significantly with age.

It should be noted that only carrying out the experiment under conditions of sufficient abundant feeding allowed large animals of a tall body type to show genetic capabilities at the age of 1.5 years, while when grown under normal economic conditions, differences in the live weight of the offspring of large and small parents become reliable only when they are older.

As shown by a number of investigations, small-scale animals finish their development earlier and at an earlier age begin to put off a significant amount of fat in the body. These animals, as more precocious are able to form a body type characteristic of adult animals much earlier. Increased fat deposition and its share in the resulting increase causes increased feed consumption per unit of growth.

As a result of the early completion of development and increased fat formation for small-scale animals, there is a faster decrease in the growth energy and when fattened they do not reach such a living mass as older animals. In the latter, the process of development is longer, fat in the body is deposited less, they last longer retain high growth energy and are able to achieve a higher live mass.

\section{Conclusion}

The results of the Aberdeen-Angus breeding bulls assessment made it possible to distinguish two main types of animals by the body type and live mass: a large tall and small compact.

The investigation results on the intensive rearing of different young stock from weaning to 18 months of age showed that bulls originating from the bulls of large-scale stud bulls exceeded bulls from small type parents for meat productivity which was expressed in a higher growth rate and better feed payment by the increase in live mass. At the age of 18 months, bulls from large-type parents reached a weight of $442 \mathrm{~kg}$, and from small ones $413 \mathrm{~kg}$. These differences are statistically significant $(\mathrm{P}>0.99)$ for the period from weaning to one and a half age, large type bulls spent $8.1 \mathrm{EFU}$ per $1 \mathrm{~kg}$ of gain, and small type bulls spent 8.4 EFU. 


\section{References}

1. V. Kulintsev, M. Shakhmurzov, A. Shevkhuzhev, V. Pogodaev, D. Smakuev, Int. J. of Engineering and Advanced Technology, 9(1), 4561-4564 (2019)

2. V. V. Onishchenko, N. S. Dega, F. H. Bostanova, Int. J. of Humanities and Natural Sciences, 1(1), 29-35 (2019)

3. P. Aparecida C. Luz, C. Andrighetto, et al., Effect of integrated croplivestock systems in carcass and meat quality of Nellore cattle Livestock Sci., 220, 83-92 (2019)

4. M. V. Tarasov, V. M. Gabidulin, V. Yu. Shmakov, Beef cattle bulletin, 63(3), 71-76 (2010)

5. O. Sheveleva, Production of beef on the basis of the development of specialized meat cattle breeding, 11, 23-27 (2008)

6. B. Chugai, A. Betin, A. Frolov, Animal husbandry of Russia, 2, 45-46 (2010)

7. A. F. Shevhuzhev, N. I. Belik, D. R. Smakuev, Research J. of Pharmaceutical, Biological and Chemical Sciences, 7,(4), 430-434 (2016)

8. Kucherenko, Animal breeding in Russia, 3, 6-7 (2009)

9. V. A. Pogodaev, V. V. Golembovsky, V. I. Komlatsky, L. F. Velichko and L. I. Konkov, IOP Conf. Series: Earth and Environmental Science, 624, 012134

10. M. Tofastrud, A. Hessle and Y.Z. B. Rekdal, Weight gain of free-ranging beef cattle grazing in the boreal forest of south-eastern Norway Livestock Sci., 2 (2020)

11. L. I. Kibkalo, V. V. Bychkov, Bulletin of the Kursk State Agricultural Academy, 1, 70$71(2010)$

12. V. Pogodaev, A. Arilov, A. Petenko, A. Soldatov, T. Pakhomova, Research J. of Pharmaceutical, Biological and Chemical Sciences, RJPBCS, 9(4), 755-759 (2018)

13. A. M. Pardo, M. A. Elzo, L. T. Gama and L. M. Melucci, Genetic parameters for growth and cow productivity traits in Angus, Hereford and crossbred cattle Livestock Sci., 233 (2020)

14. M. J. D'Occhio, P. S. Baruselli and G. Campanile, Influence of nutrition, body condition, and metabolic status on reproduction in female beef cattle, 125, 277-284 (2019) 